\title{
Fungi of Aspergillus genus in oil contaminated soils of Azerbaijan
}

Atakishiyeva Y.Y.

Institute of Microbiology of National Academy of Sciences of Azerbaijan, Baku, Azerbaijan

E-mail: y.atakishiyeva@mail.com

Key message. The thesis presents the results of studies on the species composition of fungi of Aspergillus genus in oilcontaminated gray-brown soils of Azerbaijan.

Keywords: oil-contaminated soils, micromycetes, genus, Aspergillus

Fungi genera: Alternaria, Aspergillus, Cephalosporium, Cladosporium, Fusarium, Mucor, Rhizopus and others are well known for their ability to use hydrocarbons and create the potential for oil decomposition in heterogeneous microorganisms in the environment. Genus Aspergillus is one of the most common among these fungi groups.

The purpose of this work is to isolate and study the species composition of microscopic fungi of Aspergillus genus from the oil-contaminated gray-brown soil of Azerbaijan.

20 soil samples from six main oil producing areas in Absheron were selected for this study. The hydrocarbon content in the soil was measured gravimetrically after hexane extraction. Isolation of micromycetes was performed in Czapec nutrient medium. Species identification was done by using common methods. Soil samples were provisionally divided into three groups according to the quantitative content of oil pollution: 1) contaminated soil around live drilling wells (oil pollutionabove 15\%), 2) areas of bituminized soil around old, abandoned oil derricks (oil pollution-5-10\%), 3) weathered soils with weak vegetation cover (oil pollution $-4.0-5.0 \%$ ).

Analyses have shown that in heavily oil-contaminated soils, almost all groups of microorganisms, including micromycetes, are suppressed. Overall, there were isolated 8 species of micromycetes of Aspergillus genus from the studied soils, including those not contaminated with oil: A. flavus, A. fumigatus, A. oryzae, A. ustus, A. niger, A. wentii, A. flavipes A. versicolor.

8 species of micromycetes of Aspergillus genus were isolated from the studied soil samples taken from outside of the pollution zone, 4 species isolated from weathered soils with 4.0-5.0\% oil and from areas around abandoned derricks 2 species. Among the isolated and identified aspergillus, representatives of A. fumigatus take a leading place. They dominate in all the studied soils. Representatives of $A$. niger are also present in the studied samples, but in very small amounts.

A. oryzae and $A$. wentii species were isolated only from samples of unpolluted soil and group 3. The complete absence of species A. flavipes A. versicolor and A. ustus species was noted in oil- contaminated soils.

Thus, it has been shown that the change in the species composition of microscopic fungi of Aspergillus genus is affected by the amount and period of oil pollution.

\section{Грибы рода Aspergillus в нефтезагрязненных почвах Азербайджана Атакишиева Я.Ю. Институт Микробиологии НАН Азербайджана, Баку, Азербайджан}

\begin{abstract}
Аннотация. В тезисе приведень результаты исследований по изучению видового состава грибов рода Aspergillus в загрязненных нефтью серо- бурых почвах Азербайджана.
\end{abstract}

Ключевые слова: нефтезагрязненные почвы, микромицеты, род, Aspergillus

Грибы рода Alternaria, Aspergillus, Cephalosporium, Cladosporium, Fusarium, Mucor, Rhizopus и др. хорошо известны благодаря их способности использовать углеводороды и создавать потенциал разложения нефти у разнородных микроорганизмов в окружающей среде. Род Aspergillus является одной из наиболее распространенных среди этих групп грибов.

Цель данной работы - выделение и изучение видового состава микроскопических грибов рода Aspergillus из нефтезагрязненной серо-бурой почвы Азербайджана. Для исследования были отобраны 20 почвенных образцов почв по шести основным районам нефтедобычи на Апшероне. Содержание углеводородов в грунте определяли гравиметрически после экстракции гексаном. Выделение микромицетов проводили на питательной среде Чапека. Идентификацию видов проводили общепринятыми методами.

Образцы почв были условно разделены на три группы по количественному содержанию нефтяного загрязнения: 1) замазученные земли вокруг действующих буровых скважин (нефтяное загрязнение - выше 15\%), 2) участки битумизированных земель вокруг старых, брошенных нефтяных вышек (нефтяное загрязнение - 5-10\%), 3) выветриваемые почвы со слабым растительным покровом (нефтяное загрязнение - 4,0-5,0\%).

Анализы показали, что в сильно нефтью загрязненных почвах наблюдается угнетение почти всех групп микроорганизмов, в том числе и микромицетов. Всего из исследуемых почв, в том числе и незагрязненных нефтью почв выделено 8 видов микромицетов рода Aspergillus: A. flavus, A. fumigatus, A. oryzae, A. ustus, A. niger, A. wentii, A. flavipes A. versicolor.

Из исследованных почвенных образцов, взятых из вне зоны загрязнения, было выделено 8, из выветриваемых почв с 4,0$5,0 \%$ нефтью 4 и из участков вокруг брошенных вышек 2 вида микромицетов рода Aspergillus. Среди выделенных и идентифицированных аспергиллов представители вида A. fumigatus занимают ведущее место. Они доминируют во всех исследованных почвах. Представители A. niger также присутствуют в исследованных образцах, но очень в малом количестве.

Виды A. oryzae и A. wentii были выделены только из образцов незагрязненных земель и 3-й группы. Полное отсутствие видов A. flavipes A. versicolor и A. ustus отмечено в нефтезагрязненных почвах.

Таким образом показано, что на изменение видового состава микроскопических грибов рода Aspergillus влияет количество и временной период нефтяного загрязнения. 